Research Article

\title{
Evaluation of eslicarbazepine for its antidiuretic effect in albino wistar rats
}

\author{
Satish AM ${ }^{1}$, Mohammed Sibgatullah ${ }^{1}$, Lokraj Subedee ${ }^{1}$, Shashi Kumar ${ }^{1}$, \\ Umme Salma ${ }^{1}$, Varun Gupta ${ }^{2}$
}

${ }^{1}$ Department of Pharmacology, JSS Medical College, Mysore, Karnataka, India

${ }^{2}$ Department of Pharmacology, Rohilkhand medical college, Bareilly, India

Received: 29 June 2016

Revised: 14 July 2016

Accepted: 10 August 2016

*Correspondence to:

Dr. Mohammed Sibgatullah, Email: sibgatullah2@yahoo.com

Copyright: (C) the author(s), publisher and licensee Medip Academy. This is an openaccess article distributed under the terms of the Creative Commons Attribution NonCommercial License, which permits unrestricted noncommercial use, distribution, and reproduction in any medium, provided the original work is properly cited.

\begin{abstract}
Background: Diabetes insipidus is characterized by polyuria, polydipsia with hyposthenuria, causing dehydration and hypernatremia if the patient is deprived of water. Vasopressin analogues and drugs causing water retention are used in this condition. The aim of the present study was to evaluate the antidiuretic effect of eslicarbazepine in albino rats.

Methods: The animals were divided into 3 groups each containing 6 animals. The first group was constituted by the control group which received distilled water. The second was the standard group which received vasopressin. The third group was constituted by the test group which received the test drug eslicarbazepine. The test drug was given for a period of 5 days. On 5 th day, one hour after administration of respective drugs in different groups, diuresis was induced in all groups of animals by Furosemide after they were loaded with normal saline after overnight fasting. The volume of urine collected was measured at the end of 5 hours from each of the group along with sodium, potassium and chloride concentrations.

Results: There was significant water retention and urine was concentrated in the test group which received eslicarbazepine when compared to the control group.

Conclusions: Eslicarbazepine has significant water retaining capacity in albino wistar rats. Further evaluation is required before using it in diabetes insipidus.
\end{abstract}

Keywords: Eslicarbazepine, Antidiuretic, Diabetes insipidus

\section{INTRODUCTION}

Water comprises from $75 \%$ body weight in infants to $55 \%$ in elderly and is essential for cellular homeostasis and life. Maintaining a constant water and mineral balance requires the coordination of sensitive detectors at different sites in the body linked by neural pathways with integrative centers in the brain that process this information. These centers are also sensitive to humoral factors (neurohormones) produced for the adjustment of diuresis, natriuresis and blood pressure (angiotensin mineralocorticoids, vasopressin, atrial natriuretic factor). Instructions from the integrative centres to the "executive organs" (kidney, sweat glands and salivary glands) and to the part of the brain responsible for corrective actions such as drinking are conveyed by certain nerves in addition to the above mentioned substances. ${ }^{1}$

Antidiuretic hormone released from posterior pituitary has a crucial role in control of water content of the body through its actions on the cells of the distal part of nephron and collecting tubules in the kidney. One of the main stimuli to anti diuretic hormone release is an increase in plasma osmolality which produces a sensation of thirst. A decrease in circulating blood volume i.e hypovolemia is another stimulus and here the stimuli arise from baroreceptors in cardiovascular system or from angiotensin release. Antidiuretic hormone binds to the $\mathrm{V}_{2}$ receptors in basolateral membrane of cells of distal tubule and collecting ducts of the nephron. Its main effect in 
collecting duct is to increase the rate of insertion of water channels into luminal membrane thus increasing the permeability of membrane to water thereby leading to water reabsorption from the nephron. Several drugs affect the action of antidiuretic hormone. Non-steroidal antiinflammatory drugs (NSAIDs) and carbamazepine increase and lithium, colchicines and Vinca alkaloids decrease anti-diuretic hormone effects. Demeclocycline counteracts the action of antidiuretic hormone and it can be used to treat patients with hyponatremia caused by excessive secretion of antidiuretic hormone. ${ }^{2}$

Diabetes insipidus (DI) is either due to deficient secretion of arginine vasopressin (AVP), also known as antidiuretic hormone $(\mathrm{ADH})$ by the pituitary gland (central diabetes insipidus) or due to renal tubular unresponsiveness to AVP (nephrogenic DI). This leads to polyuria, polydipsia with hyposthenuria, causing dehydration and hypernatremia if the patient is deprived of water. ${ }^{3}$

Oxcarbazepine, carbamazipine are antiepileptic drugs which are known to cause SIADH. Comparative studies have been done in human subjects to check for hyponatremic effects by $\mathrm{ADH}$ secretion between carbamazipine and oxcarbazipine. Studies show the prevalence of hyponatremia is greater in patients treated with oxcarbazepine than with carbazepine. ${ }^{4}$

Eslicarbazepine acetate is a prodrug for $(S)-(+)-$ licarbazepine, the major active metabolite of oxcarbazepine..$^{5}$ Its mechanism of action is therefore identical to that of oxcarbazepine. There may, however, be pharmacokinetic differences. Eslicarbazepine acetate may not produce as high peak levels of $(S)-(+)-$ licarbazepine immediately after dosing as does oxcarbazepine which could theoretically improve tolerability. 6

Hence this study was taken up with a rationale to look for water retaining effect of eslicarbazepine in albino wistar rats by virtue of its property of causing release of Ant diuretic hormone.

\section{METHODS}

Albino rats of either sex of average weight 150-200 gms, aged 3-4 months, of healthy rats with normal behaviour which were bred in central animal house of JSS medical college, Mysore were taken up for the study. Pregnant and diseased rats were not included in the study.

The animals were divided into 3 groups each containing 6 animals. The first group was constituted by the control group receiving $10 \mathrm{ml} / \mathrm{kg}$ body weight of distilled water. The second was the standard group which received vasopressin 4 units/intra peritoneal injection. The third group was constituted by the test group which received the test drug eslicarbazepine $200 \mathrm{mg} / \mathrm{kg}$ body weight. The test drug was given for a period of 5 days. On 5 th day, one hour after administration of respective drugs in different groups, diuresis was induced in all groups of animals by furosemide $20 \mathrm{mg} / \mathrm{kg}$ after they were loaded with normal saline $25 \mathrm{ml} / \mathrm{kg}$ after overnight fasting. ${ }^{7}$ The animals were kept in diuretic cage specially designed to separate faeces and urine at room temperature. The volume of urine collected was measured at the end of 5 hours from each of the group along with sodium, potassium and chloride concentrations.

\section{RESULTS}

There was a significant reduction in the average urine excreted in the test group when it was compared to the control group. The average urine excreted in the trial period in control group was $5 \mathrm{ml}$ whereas it was $3 \mathrm{ml}$ in the test group and $1 \mathrm{ml}$ in the standard group which received vasopressin. In terms of urine excreted in the control group considering it to be $100 \%$ in the control group, urine volume was just $20 \%$ in the vasopressin group and $60 \%$ in test group as shown in Table 1. This may signify a moderate anti-diuretic action of eslicarbazepine though not potent as standard drug vasopressin.

The electrolyte concentration shows the relatively concentrated urine in standard and test group with significant $\mathrm{P}$ values for all the electrolytes $(\mathrm{Na} / \mathrm{K} / \mathrm{Cl})$ when compared to the control group. The mean $\mathrm{Na}$ concentration was $120.5,246.7,174.1 \mathrm{mEq} / \mathrm{L}$ respectively in control, standard and test groups.The mean $\mathrm{K}$ concentration was $23.7,36.8,29 \mathrm{mEq} / \mathrm{L}$ in control, standard and test group respectively. The mean $\mathrm{Cl}$ concentration was $110.3,234.4,160.1 \mathrm{mEq} / \mathrm{L}$ in control, standard and test respectively. The values are suggestive of concentrating ability of the test drug though not as efficacious as the standard drug vasopressin.

Table 1: Urine volume in different groups of experimental animals.

\begin{tabular}{|lllll|}
\hline Group & Dose & $\begin{array}{l}\text { Volume of urine } \\
\text { in ml } \pm \text { SEM }\end{array}$ & $\begin{array}{l}\% \text { volume in terms } \\
\text { of control }\end{array}$ & $\begin{array}{l}\text { \% volume in terms of } \\
\text { standard }\end{array}$ \\
\hline Control & $\begin{array}{l}\text { Distilled water } 10 \mathrm{ml} / \mathrm{kg} \\
\text { body weight }\end{array}$ & $5 \pm 0.17$ & $100 \%$ & $500 \%$ \\
\hline Vasopressin & 4 units I.P & $1 \pm 0.25$ & $20 \%$ & $100 \%$ \\
\hline Eslicarbazepine & $200 \mathrm{mg} / \mathrm{kg}$ body weight & $3 \pm 0.10$ & $60 \%$ & $300 \%$ \\
\hline
\end{tabular}

$\mathrm{P}$ value was significant when the test drug was compared to the control in terms of urine volume. 
Table 2: Electrolyte concentration in urine.

\begin{tabular}{|llll|}
\hline Group & $\begin{array}{l}\mathbf{N a}^{+} \text {conc in } \mathbf{m E q} / \mathbf{l} \\
\text { mean } \pm \text { SEM }\end{array}$ & $\begin{array}{l}\mathbf{K}^{+} \text {conc in } \mathbf{m E q} / \mathbf{l} \\
\text { mean } \pm \text { SEM }\end{array}$ & $\begin{array}{l}\mathrm{Cl}^{-} \text {conc in } \mathbf{m E q} / \mathbf{l} \\
\text { mean } \pm \text { SEM }\end{array}$ \\
\hline Control & $120.5 \pm 2.5$ & $23.7 \pm 1.1$ & $110.3 \pm 1.8$ \\
\hline Vasopressin & $246.7 \pm 3.2$ & $36.8 \pm 0.9$ & $234.4 \pm 2.7$ \\
\hline Eslicarbazepine & $174.1 \pm 2.1$ & $29.0 \pm 1$ & $160.1 \pm 2.3$ \\
\hline
\end{tabular}

The electrolytes were very much concentrated in the standard group. The levels were almost double than that of the control group suggesting concentration of the urine. The urine sample of test group was concentrated when compared to the control group but it was less concentrated when compared to the standard group. Similarly the other urinary electrolytes i.e $\mathrm{K}^{+}$and $\mathrm{Cl}^{-}$ levels were high in the standard group but were intermediate in the test group as given in Table 2 .

The levels of electrolytes basically suggest water retention capacity of eslicarbazepine leading to concentrated urine.

\section{DISCUSSION}

The concentration of urine by administration of eslicarbazepine is reflected as decrease in urine volume which was significant when comparison was done between test group and the control group. Also the increased concentration of the urine reinforces the assumption that water retention has indeed taken place when comparison was done between test and the control group. Hyponatremia has been observed in $0.6 \%-1.3 \%$ of patients treated with eslicarbazepine during the premarketing clinical trials. ${ }^{8,9}$ This was manifestation of overt adverse effect of water retention and dilutional hyponatremia.

Our study does have drawbacks too. Only urinary electrolyte concentrations were measured, looking for effect on serum electrolytes in addition would have been ideal. A single dose of the test drug was taken; multiple doses would have shown a clearer picture about the effect of the drug. Since Carbamazepine has been used with some success in diabetes insipidus, another group in which carbamazepine as treatment drug would have been a rational approach as carbamazepine and eslicarbazepine belong to same class of drugs. ${ }^{10}$

No studies have been done on similar lines of our study in human subjects. Hence further research in required in this aspect looking for hyponatremic/water retention effect of eslicarbazepine in subjects who are taking this drug in form of serum electrolyte concentrations and urinary electrolyte concentrations.
Funding: No funding sources

Conflict of interest: None declared

Ethical approval: The study was approved by the Institutional Ethics Committee

\section{REFERENCES}

1. Nicolaidis S. Physiology of thirst. In: Arnaud MJ, editor. Hydration Throughout Life. Montrouge: John Libbey Eurotext; 1998: 247.

2. Rang HP, Ritter JM, Flower RJ. Drugs affecting major organ systems, the pituitary and the adrenal cortex. In: Rang and Dale's pharmacology, 6th edition. Elsevier; 2008: 425-426.

3. Verbalis JG. Diabetes insipidus. Rev Endocr Metab Disord. 2003;4(2):177-85.

4. Dong X, Leppik IK, White J, Rarick J. Hyponatremia associated with oxcarbazepine and sodium valproate. Neurology. 2005;65(12):1976-8.

5. Rogawski MA. Diverse Mechanisms of Antiepileptic Drugs in the Development Pipeline. Epilepsy Res. 2006;69(3):273-94.

6. Rogawski MA, Loscher W. The neurobiology of antiepileptic drugs. Nature Reviews Neuroscience. 2004;5(7):553-64.

7. Satish AM, Sibgatullah Md, Pushpa VH, Kalabharathi HL, Kishore MS, Vaibhavi PS. Evaluation of antidiuretic effect of escitalopram in albino wistar rats. World journal of pharmacy and pharmaceutical sciences. 2014;3(12):1781-4.

8. Elger C, Bialer M, Cramer JA, Maia J, Almeida L, Soares-da-Silva P. Eslicarbazepine acetate: a double-blind, add-on, placebo-controlled exploratory trial in adult patients with partial-onset seizures. Epilepsia. 2007;48(3):497-504.

9. Ben-Menachem E, Gabbai AA, Hufnagel A, Maia J, Almeida L, Soares-da-Silva P. Eslicarbazepine acetate as adjunctive therapy in adult patients with partial epilepsy. Epilepsy Res. 2010;89(2-3):278-85.

10. Bickler RN. Treatment of diabetes insipidus with carbamazepine. Lancet. 1976;2:749-52.

Cite this article as: Satish AM, Sibgatullah Md, Subedee L, Kumar S, Salma U, Gupta V. Evaluation of eslicarbazepine for its antidiuretic effect in albino wistar rats. Int J Basic Clin Pharmacol 2016;5:1914-6. 